\title{
Effects of selected fruit development factors on the quality and acceptability of vacuum-fried EVIARC sweet jackfruit (Artocarpus heterophylus Lam.) pulp
}

\author{
Roberta D. Lauzon" ${ }^{1 *}$ Lorina A. Galvez', Felix J. Amestoso' and Jennelyn P. \\ Vinculado'
}

\begin{abstract}
The study was undertaken to evaluate the effects of fruit development and conditions on the quality and acceptability of fresh and vacuum-fried jackfruit pulp from EVIARC Sweet variety.

Four maturity periods, namely, 85, 88, 91 and 94 days after bagging of fruits were considered in the study. Effect of fruit location on tree and pulp location in fruit, as well as size and thickness of pulp were the conditions evaluated. Physicochemical properties like $\mathrm{pH}$, TTA, TSS, thickness and pectin of fresh ripe pulp were evaluated while sensory attributes of vacuum-fried jackfruit pulp were determined. The attributes evaluated by semi-trained panelists were color, aroma, taste, texture, oiliness and general acceptability of vacuum-fried jackfruit pulp. Consumer acceptability was determined by subjecting the product to consumer evaluation employing students, faculty, staff, housewives and guests of the Visayas State University. It was found that fruit maturity significantly affected the quality of vacuum-fried jackfruit pulp. The ideal maturity of jackfruit for vacuum fried pulp production is 88 days after bagging. Fruit location on tree has significant influence on $\mathrm{pH}$, TSS and TA while the pulp location in fruit has significant influence on $\mathrm{pH}$, TSS and thickness. The pulp thickness did not influence the sensory acceptability ratings of all the sensory attributes. The pulp size only influenced the taste acceptability rating of the product. The taste attribute of vacuum-fried jackfruit pulp was significantly affected by the fruit location on tree, location of pulp in fruit, and pulp size. Worth noting is that mean acceptability rating still fell under the moderately acceptable level of the scale and the products were acceptable among consumers.
\end{abstract}

Keywords: EVIARC Sweet, vacuum-fried jackfruit, fruit maturity, physico-chemical properties of vacuum fried jackfruit

${ }^{1}$ Department of Food Science and Technology,Visayas State University,Visca, Baybay City, Leyte

*Corresponding Author. Address: Department of Food Science and Technology, Visayas State University, Visca, Baybay City, Leyte; Email: roberta_lauzon@yahoo.com

DOI: 10.32945/atr41110.2019 
Effects of selected fruit development factors on the quality and acceptability of vacuum-fried

\section{INTRODUCTION}

Jackfruit (Artocarpus heterophyllus, Lam.) is one of the most widely grown fruit crops in the Philippines (Coronel 1983) and one of the most famous in the world owing to the largest tree-borne edible fruit that may weigh as much as $50 \mathrm{~kg}$. It is known for its large edible bulbs of yellow, very sweet smelling, pineapple and banana-flavored flesh that enclose a smooth, oval, light-brown seed. Jackfruit is highly nutritious being reported to contain high levels of vitamins and minerals (Swani et al 2012). It also contains phenols, tannins and antioxidants specifically the EVIARC sweet variety (Galvez \& Dizon 2017) which are known to have health benefits.

Green jackfruit is usually used for vegetables while ripe jackfruit is usually consumed as fresh fruits. Other regions used the ripe jackfruit bulb as ingredient in native delicacies like "guinata-an" and filling of "banana turon" or banana roll and as flavorant of ice cream and other frozen desserts.

The Visayas State University (VSU) through the Department of Food Science and Technology (DFST) developed vacuum-fried jackfruit pulp from ripe bulbs of jackfruit specifically the EVIARC Sweet variety. The product was highly acceptable among consumers of all ages and even among foreign guests of the university. The high acceptability of vacuum-fried jackfruit encouraged DFST to commercialize the product. The current vacuum frying technology for jackfruit and operated at VSU has shown great potential for the conversion of jackfruit pulp into a commercial product. Diamante (2007) pointed out that commercialization of vacuum-fried jackfruit provides a way of adding real value to the crop and reinforces its promotion as a viable crop for farmers to go into. The popularity and high demand for vacuumfried jackfruit encourages a number of processors to adapt the vacuum frying technology. However, the current vacuum frying technology has some constraints to be addressed.

Uneven color, occasional browning, bland taste, less aromatic and less crispy fried pulps are some identified problems in the current vacuum-fried jackfruit technology which are believed to be influenced by some fruit development factors. Pale color, bland taste and absence of jackfruit aroma were noted in vacuum-fried pulp from under ripe jackfruit while brownish yellow color and less crunchy was perceived in vacuum-fried pulp from overripe fruit.

Standardization of fruit maturity and pulp quality is necessary in order to achieve and maintain product quality. This study was conducted to determine the effect of selected fruit development factors like maturity, fruit location on tree, location of pulp in fruit and pulp size and thickness on the quality and acceptability of vacuum-fried jackfruit pulps.

\section{MATERIALS AND METHODS}

\section{Procurement of Materials}

The fruits (EVIARC Sweet) were procured from the farm of "Magsasakang Siyentista" or Farmer Scientist from Mahaplag, Leyte. Arrangements were made with the Magsasakang Siyentista to provide dedicated jackfruit trees as source of fruits for the study. The freshly harvested jackfruit with identified maturity was carefully harvested from the farm and brought to DFST for evaluation. 


\section{Physicochemical Properties}

Moisture content, $\mathrm{pH}$, titratable acidity (TTA), total soluble solids (TSS) and pectin content of jackfruit pulp from 88, 91 and 94 days old fruit were analyzed following the method set by AOAC (1980).

Moisture Content (MC). Moisture content of the product was determined using Force Draft Oven for $24 \mathrm{~h}$ at $105^{\circ} \mathrm{C}$. Five (5) grams of jackfruit pulp from different fruit maturity was separately weighed and placed into previously tared crucibles. The crucibles were dried for 24 hours or until weight of the sample became constant for 3 consecutive readings. The moisture content of the samples was computed following the formula below:

$$
\% \mathrm{MC}=\frac{\mathrm{W} 1-\mathrm{W} 2}{\mathrm{~W} 1} \times 100
$$

Where:

$$
\begin{aligned}
& W 1=\text { initial weight } \\
& W 2=\text { final weight of sample } \\
& 100 \text { - constant figure }
\end{aligned}
$$

pH. Ten (10) grams of homogenized sample was weighed and added with $10 \mathrm{ml}$ distilled water and mixed well. The mixture was centrifuged and the supernatant was collected and used in the determination of $\mathrm{pH}$ of the sample. The evaluation was conducted three times and the average of the three readings was used in reporting the data.

TTA. The TTA of the sample was determined employing the methods set by AOAC (1980). Five grams of finely crushed sample was diluted with $25 \mathrm{ml}$ distilled water and mixed well. The mixture was added with 3-4 drops of phenolphthalein indicator and properly mixed. The mixture was titrated with $0.1 \mathrm{~N} \mathrm{NaOH}$ until a pale pink color appeared. Percent TTA (\% ascorbic acid) was computed using the given formula.

$$
\begin{gathered}
\% \mathrm{TTA}(\text { ascorbic acid })=\frac{\text { Volume }_{\mathrm{NaOH}} \times \text { Normality }_{\mathrm{NaOH}} \times \mathrm{meq}_{\text {acid }}}{\text { Weight of Sample }} \times 100 \\
\text { Weight of sample }=\frac{\text { weight of sample }(\mathrm{g}) \times \text { weight of aliquot }}{\text { Weight of sample }+ \text { weight of water }}
\end{gathered}
$$

Total Soluble Solids (TSS). The TSS of the sample was determined using a laboratory hand refractometer. A drop of sample was placed on the prism of the instrument. The lid was closed and the instrument was directed towards light source to get a clear sight of the reading. The TSS was calculated and computed based on the formula below;

$$
\begin{gathered}
\text { TSS }=\text { dilution factor }(\mathrm{DF}) \mathrm{x}^{\circ} \mathrm{B} \\
\mathrm{DF}=\frac{1+\text { volume of water added }(\mathrm{ml})}{\text { Weight of sample }(\mathrm{g})} \\
\text { Where } 1 \mathrm{ml} \text { water }=1 \mathrm{~g} \text { water }
\end{gathered}
$$


Effects of selected fruit development factors on the quality and acceptability of vacuum-fried

Pectin. Jackfruit pulp from fruit of different maturity was separately collected and placed in a separate container. One hundred (100) grams of fruit pulp was chopped and separately placed into a sauce pot. Equal amount of water was added and the mixture was boiled for 3 minutes. Fifteen $\mathrm{ml}$ of the extract was collected in a clean flask. Fifty $\mathrm{ml}$ of denatured alcohol was added into the flask and the mixture was slowly stirred with glass rod and allowed to stand undisturbed to allow for the formation of pectin lumps. The pectin was collected by allowing the mixture to pass through a pre-weighed filter paper. The pectin was allowed to dry on the filter paper and re-weighed. The weight of pectin was determined by subtracting the weight of pectin by the weight of filter paper and recorded as gram pectin per $100 \mathrm{~g}$ pulp.

\section{Fruit Preparation and Evaluation}

Effect of Fruit Maturity. Twenty (20) fruits of same age were harvested from the dedicated trees. The fruit age was 85 days after bagging as identified by the Magsasakang Siyentista. The fruits were grouped into four with 5 fruits per group. Each group was considered a treatment; T1 - 85 days, T2 - 88, T3 - 91 and T4 - 94 days). The fruits were allowed to ripen at ambient condition.

The fruits of different maturity, ie, 85, 88, 91 and 94 days were washed with diluted dishwashing solution, rinsed with tap water and dipped in $10 \mathrm{ppm}$ chlorinated water. The fruits were split opened and separately depulped and deseeded. The pulp from different fruit maturity was separately blanched, drained, packed and frozen. The frozen pulps were vacuum-fried employing the vacuum frying schedule set by Diamante (2007). The vacuum-fried pulps were spin dried to remove the excess frying oil, packed and sealed and kept in close container ready for evaluation.

The identified fruit maturity suitable for vacuum frying was the maturity of fruits used on the succeeding fruit quality evaluation.

Effects of Fruit Location on Tree. Nine fruits of the same maturity ( 85 days) were used in the study. Fruit selection was based on their location on the tree. Three fruits from upper part, another three from middle portion and another three from lower part of the tree. The fruit location were considered as treatments of the study. Upon harvest, the fruits were brought to the laboratory for ripening at room condition. The pulps of ripe jackfruit were separately collected and processed into vacuum fried jackfruit following the method of Diamante (2007) with modifications.

Effect of Pulp Location on Fruits. Five fruits of same maturity (85 days) were harvested and allowed to ripen at laboratory condition. After three days of keeping the fruits at laboratory, the fruits were separately washed with mild detergent, washed with potable water and sanitized in $10 \mathrm{ppm}$ chlorinated water and split opened. Pulps were separately collected from three fruit locations, the upper, middle and bottom portion of the fruit. The pulps were separately deseeded, blanched and frozen ready for vacuum frying. The pulp locations in fruit are considered treatment of the study.

Effect of Pulp Size. Fruits were washed with mild dishwashing solution, rinsed with tap water and dipped in 10ppm chlorinated water. The clean fruits were split opened, depulped and the fruit pulps were arbitrarily grouped into small, medium, and large. Twenty-five pieces of fresh bulb were collected from each size category and separately placed into a clean container. The pulps were deseeded, blanched, drained and allowed to cool, packed and frozen. The frozen pulp of different sizes were separately vacuum-fried, spin-dried, packed and kept ready for evaluation. 
Pulp Thickness. Fruit pulps from fruits with identified maturity were collected and deseeded. The pulps were split-opened and seeds were removed. They were sorted and arbitrarily grouped as thin, thick, and thicker. Thickness was determined using Vernier caliper. The pulps with different thickness were separately blanched, drained, allowed to cool and frozen. The frozen jackfruit pulps with different pulp thickness were separately vacuum-fried, spin-dried, packed and kept ready for evaluation.

\section{Sensory Evaluation}

The samples that got the highest mean acceptability rating based on the result of sensory evaluation were the sample subjected to consumer evaluation. For fruit maturity, the 88-day sample was used because it was the treatment that got a significantly higher mean general acceptability rating. Samples from fruits located on tree, fruit pulp located in fruit, and different pulp size and thickness were all subjected to consumer evaluation because their mean general acceptability ratings did not significantly differ from each other.

The consumer evaluation was carried out employing 100 consumers consisting of students, faculty, staff and guests of the university. The sensory evaluation of the different treatments was carried out employing the laboratory test panel composed of thirty 32 fourth year students, faculty and staff of the Department of Food Science and Technology of the Visayas State University, Visca, Baybay City, Leyte. Sensory evaluation was carried out using the method set by Mabesa (1986). Samples were randomly coded with three-digit numbers and presented to the panelists who evaluated the vacuum-fried jackfruits according to their color, aroma, taste, texture, oiliness and general acceptability using quality scoring in combination in the 9-Point Hedonic scale.

\section{Consumer Evaluation}

The consumer evaluation was done by 100 consumers consisting of students, faculty, staff and guests of the university. The consumers were individually given samples of the most acceptable vacuum-fried jackfruit pulp together with the control sample. The control sample was the vacuum-fried jackfruit pulp commercially produced by the Baybay Women Association who adopted the processing technology. The consumers were asked to rate the product based on their own judgement. Each consumer was given a scorecard and pen for them to write their answers. The percentage of consumers who liked or preferred the product was determined by dividing the total like responses by the total number of consumers who evaluated the product and the answer was multiplied by one hundred.

$$
\% \text { acceptability }=\frac{\text { No. of like answers }}{\text { Total no. of consumers who evaluated the product }} \times 100
$$

\section{RESULTS AND DISCUSSIONS}

\section{PhysicoChemical Properties}

The physicochemical properties of EVIARC Sweet jackfruit as influenced by fruit maturity is presented in Table 1. Results revealed that fruit maturity significantly influenced the physicochemical properties of fresh jackfruit pulp. 
Effects of selected fruit development factors on the quality and acceptability of vacuum-fried

Table 1. Physicochemical properties of fresh jackfruit pulp as influenced by fruit maturity

\begin{tabular}{|c|c|c|c|c|c|}
\hline $\begin{array}{l}\text { Maturity } \\
\text { (Days) }\end{array}$ & $\begin{array}{c}\text { Moisture } \\
\text { Content** } \\
(\%)\end{array}$ & $\begin{array}{l}\text { Pectin* } \\
\text { (g) }\end{array}$ & $\mathrm{pH}^{*}$ & $\begin{array}{l}\text { TTA** } \\
(\% A A)\end{array}$ & $\begin{array}{c}\text { TSS** } \\
\left({ }^{\circ} \mathrm{B}\right)\end{array}$ \\
\hline 85 & $5.89 \mathrm{~d}$ & $3.63 \mathrm{a}$ & $4.4 \mathrm{c}$ & $0.0596 \mathrm{~d}$ & $16.93 d$ \\
\hline 88 & $6.62 c$ & $2.67 \mathrm{~b}$ & $4.9 \mathrm{~b}$ & $0.1357 \mathrm{c}$ & $33.88 \mathrm{a}$ \\
\hline 91 & $8.60 \mathrm{~b}$ & $2.66 \mathrm{~b}$ & $5.0 \mathrm{~b}$ & $0.1603 \mathrm{~b}$ & $30.33 b$ \\
\hline 94 & $12.82 a$ & $2.62 \mathrm{c}$ & $5.3 \mathrm{a}$ & $0.2334 \mathrm{a}$ & $27.35 \mathrm{c}$ \\
\hline
\end{tabular}

*- significant $\quad * *$-highly significant

Moisture Content. Pulp from fruit harvested 85 days after bagging had significantly lower moisture content of $5.89 \%$. Increasing the fruit maturity to 88,91 and 94 days increased the moisture content to $6.62,8.60$ and $12.82 \%$, respectively, which is significantly different from each other. The significantly higher moisture content of pulp from 94-day fruits can be attributed to the conversion of pectin to Free-D galacturonic acid, a water soluble compound that makes the overripe fruit watery (Raymundo 1989). This finding can be supported by the result in pectin determination as shown in Table 1 wherein pulp from 94-day fruits got significantly lower pectin content.

Pectin Content. Fruit maturity had significant effect on pectin content of the pulp. Pectin content was significantly higher in fruit pulp from 85-day fruits. As maturity period increased to 88,91 and 94 days, a significant decrease in pectin content was observed from $3.63 \mathrm{~g}, 2.67 \mathrm{~g}$ and $2.66 \mathrm{~g}$, respectively and significantly lower pectin content of $2.62 \mathrm{~g}$ in fruit pulp from 94-day fruits. Pectin content was indirectly proportional to the fruit maturity period and moisture content of the pulp. The significant decrease in pectin content of pulp from 94-days fruits was due to the action of enzymes on pectin that resulted in pectin degradation.

pH. The pH value of jackfruit pulp was significantly influenced by maturity. Results show that as fruit maturity increased from 85 days to 88,91 and 94 days, $\mathrm{pH}$ value of the pulp significantly increased from 4.6 to $4.9,5.0$ and 5.3, respectively, making the pulp slightly acidic.

TSS. The total soluble solids of jackfruit pulp from 85-day matured fruits had the lowest TSS value of $16.93^{\circ} \mathrm{B}$. Increasing the maturity to 88 days, resulted in a significantly higher TSS of $33.88^{\circ} \mathrm{B}$. Increasing further fruit maturity to 91 and 94 days, resulted in significantly lower TSS value to 30.3 and $27.35^{\circ} \mathrm{B}$, respectively. It is possible that upon maturity, the sugar in fruit pulp was converted into fruit acid as exhibited by the increasing value of titratable acidity (Table 1). Of the fruit maturity evaluated, the 88 -day had significantly higher TSS of $33.88^{\circ} \mathrm{B}$ than other treatments.

TTA. The TTA of 85 -day pulp was $0.0596 \%$ significantly lower than its counterparts. Increasing the maturity period to 88 days significantly increased the TTA of fresh pulp to $0.1357 \%$. Further increase of maturity period to 91 and 94 days significantly increased TTA. TTA of pulp from 94-day fruits was $0.2334 \%$ significantly higher than all the other samples evaluated (Table 1). 


\section{Effect of Maturity on Sensory Attributes}

Quality Description. The description of quality attributes of vacuum-fried jackfruit from EVIARC Sweet variety as influenced by fruit maturity is presented in Table 2. The colors of vacuum-fried pulp from 85- and 88-day old fruit were described "light yellow" to "dark yellow". Increasing the maturity period to 91 and 94 days resulted to a "golden yellow" to "brownish yellow" color. The darkening in color of vacuum-fried pulp from 91- and 94-day fruits can be attributed to the increase of sugar on the pulp as shown from Table 2. The sugar caramelized upon frying of the pulp. The more sugar caramelized, the darker was the color of the product. As observed, sugar leached out from fruit upon frying and the caramelized sugar adhered to the surface of the fried pulp and resulted in the browning of the product. The aroma of vacuum-fried pulp from 85-day fruit was described "slightly perceptible jackfruit aroma" while a "very perceptible jackfruit aroma" was perceived in fruits processed from 88, 91 and 94-day fruits. For taste, a "slightly sweet taste" was noted in product from 85 days. Increasing the fruit maturity to 88 , 91 and 94 days resulted in a "moderately sweet" to "very sweet taste" vacuum-fried pulp. Ripening of fruits increased sugar content that contributed to the sweetness of the fruit. The texture of vacuum-fried jackfruit was perceived "very crispy" regardless of fruit maturity. The oiliness of vacuum-fried pulp was influenced by fruit maturity. Vacuum-fried pulp from 85 days was perceived "not oily". However, the oiliness description of vacuum-fried pulp from 88, 91 and 94-day fruit ranged from "not oily" to "slightly oily".

Table 2. Quality description of vacuum-fried pulp from EVIARC Sweet variety as influenced by fruit maturity

\begin{tabular}{|c|c|c|c|c|c|c|}
\hline \multirow{2}{*}{ Treatment } & \multirow{2}{*}{ Days } & \multicolumn{5}{|c|}{ Quality Description } \\
\hline & & Color & Aroma & Taste & Texture & Oiliness \\
\hline 1 & 85 & $\begin{array}{l}\text { Light yellow } \\
\text { to dark } \\
\text { yellow }\end{array}$ & $\begin{array}{l}\text { Slightly } \\
\text { perceptible } \\
\text { jackfruit } \\
\text { aroma }\end{array}$ & $\begin{array}{l}\text { Slightly } \\
\text { sweet }\end{array}$ & Very crispy & Not oily \\
\hline 2 & 88 & $\begin{array}{l}\text { Light yellow } \\
\text { to dark } \\
\text { yellow }\end{array}$ & $\begin{array}{c}\text { Very } \\
\text { perceptible } \\
\text { jackfruit } \\
\text { aroma }\end{array}$ & $\begin{array}{l}\text { Moderately } \\
\text { sweet to } \\
\text { very sweet }\end{array}$ & Very crispy & $\begin{array}{l}\text { Not oily to } \\
\text { slightly oily }\end{array}$ \\
\hline 3 & 91 & $\begin{array}{l}\text { Golden } \\
\text { yellow to } \\
\text { brownish } \\
\text { yellow }\end{array}$ & $\begin{array}{c}\text { Very } \\
\text { perceptible } \\
\text { jackfruit } \\
\text { aroma }\end{array}$ & $\begin{array}{l}\text { Moderately } \\
\text { sweet to } \\
\text { very sweet }\end{array}$ & Very crispy & $\begin{array}{l}\text { Not oily to } \\
\text { slightly oily }\end{array}$ \\
\hline 4 & 94 & $\begin{array}{l}\text { Golden } \\
\text { yellow to } \\
\text { brownish } \\
\text { yellow }\end{array}$ & $\begin{array}{c}\text { Very } \\
\text { perceptible } \\
\text { jackfruit } \\
\text { aroma }\end{array}$ & $\begin{array}{l}\text { Moderately } \\
\text { sweet to } \\
\text { very sweet }\end{array}$ & Very crispy & $\begin{array}{l}\text { Not oily to } \\
\text { slightly oily }\end{array}$ \\
\hline
\end{tabular}


Effects of selected fruit development factors on the quality and acceptability of vacuum-fried

General Acceptability. The mean general acceptability rating of vacuum-fried jackfruit pulp as influenced by fruit maturity is tabulated in Table 3 . Results show that fruit maturity significantly influenced product acceptability. The color of vacuum-fried pulp from 85-day fruit got a significantly higher mean acceptability rating of 8.05 , equivalent to "like very much" and significantly higher than 88 days maturity whose mean rating was 7.77 , which corresponds to "like moderately". This was significantly higher than 91 and 94 days with mean acceptability rating of 5.94 and 4.91, leaning towards "like slightly" and "neither like nor dislike" category of the 9-point Hedonic scale, respectively.

For aroma, vacuum-fried pulp from 88-day fruit got an average mean of 8.05 equivalent to "like very much" and significantly higher than pulp of 85- and 91-day fruit whose mean acceptability rating is 7.00 and 7.52 , respectively which fall under the "like moderately" category of the 9-point Hedonic scale. The same observation was noted in taste attribute wherein vacuum-fried pulp from 88-day fruit got a mean rating of 8.14 corresponding to "like very much" and significantly higher than vacuum-fried pulp from 91-day fruit whose mean rating is 7.83 equivalent to "like moderately" category of the scale. Of the treatments evaluated, vacuum-fried pulp from 88- and 94-day fruits got a significantly lowest mean acceptability rating of 6.39 and 6.82, respectively, which correspond to "like slightly" category of the scale. Fruit maturity had no significant influence on textural quality of vacuum-fried pulp. Regardless of fruit maturity, the product got a mean acceptability rating that ranged from 7.38 to 7.80 and did not differ significantly from each other. Oiliness in vacuum-fried pulp was significantly affected by fruit maturity. Vacuum-fried pulp from 85-day fruit got the significantly highest mean acceptability rating for oiliness which was 7.44 and fall between "like moderately" to "like very much" and significantly higher than vacuum-fried pulp from 88, 91 and 94 days fruit with mean acceptability rating of $7.06,6.66$ and 6.14 , respectively. For general acceptability, vacuum-fried pulp from 88 days fruit got the highest mean acceptability rating of 8.11 corresponding to "like very much" and considered the suitable maturity of EVIARC Sweet jackfruit for vacuum-fried pulp production. The highest acceptability rating of vacuum-fried pulp from 88 days can be attributed to the sweet taste and perceptible jackfruit aroma of the product which was somehow influenced by the high TSS and TTA of the pulp (Table 4).

Table 3. Mean ${ }^{1}$ acceptability ratings ${ }^{2}$ of the sensory attributes of vacuum-fried jackfruit from pulp of EVIARC Sweet variety as influenced by fruit maturity

\begin{tabular}{|c|c|c|c|c|c|c|c|c|}
\hline \multirow[b]{2}{*}{ Treatment } & \multirow[b]{2}{*}{ Days } & \multicolumn{7}{|c|}{ Sensory Attributes } \\
\hline & & Color** & \multicolumn{2}{|c|}{ Aroma** } & Taste $^{\star \star}$ & Texture $^{\text {ns }}$ & Oiliness** & $\begin{array}{c}\text { Gen. } \\
\text { Acc.** }\end{array}$ \\
\hline 1 & 85 & $8.08 \mathrm{a}$ & \multicolumn{2}{|c|}{$7.00 \mathrm{c}$} & $6.39 \mathrm{c}$ & 7.80 & $7.44 \mathrm{a}$ & $7.27 \mathrm{~b}$ \\
\hline 2 & 88 & $7.77 \mathrm{~b}$ & \multicolumn{2}{|c|}{$8.05 \mathrm{a}$} & $8.14 \mathrm{a}$ & 7.85 & $7.06 \mathrm{~b}$ & $8.11 \mathrm{a}$ \\
\hline 3 & 91 & $5.94 \mathrm{c}$ & \multicolumn{2}{|c|}{$7.52 \mathrm{~b}$} & $7.83 \mathrm{~b}$ & 7.47 & $6.66 \mathrm{c}$ & $7.21 \mathrm{~b}$ \\
\hline 4 & 94 & $4.91 \mathrm{~d}$ & \multicolumn{2}{|c|}{$6.71 \mathrm{~d}$} & $6.82 \mathrm{c}$ & 7.38 & $6.14 \mathrm{~d}$ & $6.16 \mathrm{c}$ \\
\hline${ }^{1} \mathrm{~N}=24$ & \multicolumn{2}{|c|}{ *- significant } & \multicolumn{4}{|c|}{ ** - highly significant } & \multicolumn{2}{|c|}{ ns - not significant } \\
\hline \multicolumn{9}{|c|}{${ }^{2}$ Range of scores: } \\
\hline \multicolumn{2}{|c|}{$\begin{array}{l}9 \text { - like extremely } \\
8 \text { - like very much }\end{array}$} & \multicolumn{2}{|c|}{$\begin{array}{l}7 \text { - like moderately } \\
6 \text { - like slightly }\end{array}$} & \multicolumn{3}{|c|}{$\begin{array}{l}5 \text { - neither like nor dislike } \\
4 \text { - dislike slightly }\end{array}$} & \multicolumn{2}{|c|}{$\begin{array}{l}3 \text {-dislike moderately } \\
2 \text { - dislike very much } \\
1 \text {-dislike extremely }\end{array}$} \\
\hline
\end{tabular}


Consumer Evaluation. The 88 days fruit maturity was chosen as the best treatment and subjected to consumer evaluation since it had high TSS, more acceptable with respect to aroma, taste and general acceptability. Results revealed that vacuum-fried pulp from 88-day fruit was acceptable among $99 \%$ of the consumers higher than the existing vacuum-fried product with consumer acceptability of $92 \%$ (Table 4 ). The high consumer acceptability of vacuum-fried jackfruit from 88-day pulp was because of its attractive uniform color, sweeter taste, distinct jackfruit aroma and thicker pulp. Non-uniformity in color was observed in sample B.

Table 4. Consumers* acceptability towards vacuum-fried pulp from 88 days fruit compared with the existing product

\begin{tabular}{ccccc}
\hline \multirow{2}{*}{ Sample } & \multicolumn{5}{c}{ Consumers Response } \\
\cline { 2 - 5 } & Like & Dislike & No Comment & Total \\
\hline Sample A & 99 & - & 1 & 100 \\
Sample B & 92 & 2 & 6 & 100 \\
\hline
\end{tabular}

* Students, faculty and staff of VSU, guests of the university; A-VFJ using the 88 days maturity, B- Existing VFJ processed by the adoptors

\section{Influence of Fruit Location on the Quality of Jackfruit Pulp}

PhysicoChemical Properties. Location of fruit on tree has significant effect on $\mathrm{pH}$, TSS and TA of jackfruit pulp but not on pulp thickness. The pulp from fruit located at the lower part of the tree had $\mathrm{pH}$ value of 4.80 significantly higher than pulp of fruit located from top and middle portion of the tree with $\mathrm{pH}$ values of 3.92 and 4.11, respectively. Fruit from top of the tree got a significantly higher TSS of $31.0^{\circ} \mathrm{B}$ higher than the TSS of pulp from fruit located at the middle and bottom portion of the tree whose TSS value of $26.4^{\circ} \mathrm{B}$ and $27.0^{\circ} \mathrm{B}$, respectively and did not significantly differ from each other. For TTA, pulp from fruit taken from top part got TTA value of $0.57 \%$ which is significantly higher than the TTA of pulp from the fruit located at the middle part with TTA value of $0.44 \%$. Pulp from fruit located at the lower part of the tree got a significantly lower TTA of $0.26 \%$. In terms of pulp thickness, fruit location on tree had no significant effect on the thickness of pulp. Regardless of the fruit location on tree the pulp from top, middle and bottom got a thickness of $3.12,3.02$ and $3.40 \mathrm{~mm}$, respectively (Table 5).

Table 5. Physicochemical properties of pulp as influenced by fruit location on tree

\begin{tabular}{ccccc}
\hline Fruit Location & $\mathrm{pH}^{\star \star}$ & $\begin{array}{c}\text { TSS**} \\
\left({ }^{\circ} \mathrm{B}\right)\end{array}$ & $\begin{array}{c}\text { TTA }^{\star \star} \\
(\%)\end{array}$ & $\begin{array}{c}\text { Thickness }^{\text {ns }} \\
(\mathrm{mm})\end{array}$ \\
\hline Top & $3.96 \mathrm{~b}$ & $31.0 \mathrm{a}$ & $0.57 \mathrm{a}$ & 3.12 \\
Middle & $4.11 \mathrm{~b}$ & $26.4 \mathrm{~b}$ & $0.44 \mathrm{~b}$ & 3.02 \\
Lower & $4.80 \mathrm{a}$ & $27.0 \mathrm{~b}$ & $0.26 \mathrm{c}$ & 3.40 \\
\hline
\end{tabular}


Effects of selected fruit development factors on the quality and acceptability of vacuum-fried

Sensory Quality of Vacuum Fried Pulp. Result in sensory evaluation of vacuum fried jackfruit pulp as influenced by the location of fruit on tree is summarized in Table 6 . Location of fruit on tree significantly affected the taste acceptability only, but not the other sensory parameters. The mean acceptability ratings of the product ranged from 7.10-7.90 and fall within the "like moderately" category of the 9-point Hedonic scale. Result implies that regardless of the location of fruit on tree where the pulps were taken, the vacuum-fried pulp is acceptable.

Table 6. Mean ${ }^{1}$ acceptability ratings ${ }^{2}$ of vacuum fried jackfruit pulp as influenced by the location of fruit on tree

\begin{tabular}{ccccccc}
\hline \multirow{2}{*}{$\begin{array}{c}\text { Fruit } \\
\text { Location }\end{array}$} & \multicolumn{5}{c}{ Sensory Attributes } \\
\cline { 2 - 5 } & Color $^{\text {ns }}$ & Aroma $^{\text {ns }}$ & Taste $^{*}$ & Texture $^{\text {ns }}$ & Oiliness $^{\text {ns }}$ & Gen. Acc. $^{\text {ns }}$ \\
\hline Top & 7.20 & 7.13 & $7.90 \mathrm{a}$ & 7.10 & 7.50 & 7.8 \\
Middle & 7.18 & 7.10 & $7.67 \mathrm{~b}$ & 7.13 & 7.54 & 7.7 \\
Lower & 7.10 & 7.11 & $7.60 \mathrm{~b}$ & 7.09 & 7.50 & 7.7 \\
\hline
\end{tabular}

${ }^{1} \mathrm{~N}=24$

${ }^{2}$ Range of scores:

$$
\begin{array}{llll}
9 \text {-like extremely } & 7 \text {-like moderately } & 5 \text {-neither like nor dislike } & 3 \text {-dislike moderately } \\
8 \text {-like very much } & 6 \text {-like slightly } & 4 \text {-dislike slightly } & 2 \text {-dislike very much } \\
& & & 1 \text {-dislike extremely }
\end{array}
$$

Consumer Acceptability. Result in consumer evaluation is presented in Table 7. Result in sensory evaluation shows that out of 100 consumers who evaluated the product, 97\% liked Sample A; 96\%, Sample B; 93\%, Sample C; and 90\%, control. Results imply that the vacuum fried jackfruit, regardless of the location of fruit on tree, is acceptable among consumers.

Table 7. Consumers ${ }^{1}$ acceptability toward vacuum-fried pulp from fruit located at the top, middle and lower portion of the tree

\begin{tabular}{cccc}
\hline \multirow{2}{*}{ Sample } & \multicolumn{3}{c}{ Consumers Response } \\
\cline { 2 - 3 } & Like & Dislike & No Comment \\
\hline A (Top) & 97 & - & 3 \\
B (Middle) & 96 & - & 4 \\
C (Lower) & 93 & - & 7 \\
D (control) & 90 & - & 10 \\
\hline
\end{tabular}

'N = 100 consumers student, , faculty, staff and employee

Effect of Pulp Location in Fruit. The location of pulp in the fruit had significant influence on the $\mathrm{pH}, \mathrm{TSS}$ and pulp thickness but not on TSS of the pulp. $\mathrm{pH}$ of pulp located at the upper part of the fruit was 4.22 and significantly lower than the pH of pulp located at the middle and bottom portion of fruit which was 4.47 and 4.45 respectively and did not significantly differ from each other. In terms of TSS, pulp from the bottom part of the fruit had the highest TSS value of $26.98^{\circ} \mathrm{B}$, which was significantly higher than the TSS of pulp taken from the middle and upper part of the fruit with TSS value of 24.63 and $24.41^{\circ} \mathrm{B}$, respectively, which is significantly lower 
than TSS of pulp from the bottom of the fruit. For pulp thickness, pulp from the middle part of the fruit has average thickness of $5.30 \mathrm{~mm}$ which was significantly higher than pulp from upper and lower part of the tree with thickness value of 3.62 and 3.56, respectively, and did not differ significantly from each other.

Table 8. pH, TSS, TTA and thickness of pulp as influenced by their locations in fruit

\begin{tabular}{ccccc}
\hline Pulp Location & $\mathrm{pH}^{*}$ & $\begin{array}{c}\text { TSS* } \\
\left({ }^{\circ} \mathrm{B}\right)\end{array}$ & $\begin{array}{c}\text { TTA }^{\text {ns }} \\
(\%)\end{array}$ & $\begin{array}{c}\text { Thickness* } \\
(\mathrm{mm})\end{array}$ \\
\hline Upper & $4.22 \mathrm{~b}$ & $24.41 \mathrm{~b}$ & 0.68 & $3.02 \mathrm{~b}$ \\
Middle & $4.47 \mathrm{a}$ & $24.63 \mathrm{~b}$ & 0.56 & $4.00 \mathrm{a}$ \\
Lower & $4.45 \mathrm{a}$ & $26.95 \mathrm{a}$ & 0.65 & $3.56 \mathrm{~b}$ \\
\hline
\end{tabular}

Sensory Evaluation. Result in sensory evaluation of vacuum fried jackfruit pulp as influenced by location of pulp in the fruit is presented in Table 9. Results showed that pulp location in fruit has no significant influence in all sensory attributes evaluated except on taste attribute. In terms of taste, pulp from upper part of the fruit got a mean acceptability rating of 7.81 closer to "like very much" and significantly higher than sample from middle and lower part of the fruit whose mean acceptability rating of 7.35 and 7.0 , respectively and are significantly different from each other and fall under the "like moderately" category of the 9-point Hedonic scale. This result is inconsistent with the TSS data since the pulps found in the upper location got the lowest TSS implying lower concentration of sugar and pulps located in the lower location of the fruit got the highest TSS signifying higher sugar concentration. Probably the panelists were not able to detect well the sweetness that they significantly liked better the pulp located at the upper portion of the fruit than the pulps found in the middle or bottom of the fruit. This result is understandable since the sensory evaluation in this case is just measuring the acceptability of the taste, not the intensity of sweetness.

Table 9. Mean ${ }^{1}$ acceptability ratings ${ }^{2}$ of vacuum fried pulp as influenced by the location of pulp in the fruit

\begin{tabular}{ccccccc}
\hline \multirow{2}{*}{$\begin{array}{c}\text { Pulp } \\
\text { Location }\end{array}$} & \multicolumn{5}{c}{ Sensory Attributes } \\
\cline { 2 - 6 } & Color $^{\text {ns }}$ & Aroma $^{\text {ns }}$ & Taste* & Texture $^{\text {ns }}$ & Oiliness $^{\text {ns }}$ & Gen. Acc $^{\text {ns. }}$ \\
\hline Upper (top) & 7.30 & 7.50 & $7.81 \mathrm{a}$ & 7.15 & 7.57 & 7.60 \\
Middle & 7.28 & 7.19 & $7.35 \mathrm{~b}$ & 7.14 & 7.60 & 7.61 \\
$\begin{array}{c}\text { Bottom } \\
\text { (lower) }\end{array}$ & 7.25 & 7.17 & $7.00 \mathrm{c}$ & 7.10 & 7.55 & 7.61
\end{tabular}

${ }^{1} \mathrm{~N}=24$

${ }^{2}$ Range of scores:

9 -like extremely $\quad 7$-like moderately 5 -neither like nor dislike 3 -dislike moderately

8 -like very much 6 -like slightly $\quad 4$-dislike slightly 2 -dislike very much

1 - dislike extremely 
Effects of selected fruit development factors on the quality and acceptability of vacuum-fried

Consumer Evaluation. Results in consumer evaluation revealed that location of pulp in the fruit has no influence on consumer acceptability towards the product. All the samples evaluated regardless of their location in fruit got a high consumer acceptability. Sample A got $97 \%$ consumer acceptability; sample B, 98\%; sample C, $98 \%$; and control sample, $90 \%$. Result implies that regardless of pulp location, the product is acceptable to consumers.

Table 10. Acceptability of vacuum fried pulp taken from different locations in the fruit

\begin{tabular}{cccc}
\hline Sample/Pulp & \multicolumn{3}{c}{ Consumer Response $^{1}$} \\
\cline { 2 - 4 } Location & Like & Dislike & No Comment \\
\hline A (upper/top) & 97 & - & 3 \\
B (middle) & 98 & - & 2 \\
C (bottom/lower) & 98 & - & 2 \\
D control & 96 & - & 4 \\
\hline
\end{tabular}

${ }^{1} \mathrm{~N}=100$ consumer composed of students, staff, faculty of VSU

\section{Effect of Pulp Thickness}

Quality Description. Quality description of the sensory attributes of vacuumfried jackfruit as influenced by pulp thickness is presented in Table 11. In terms of color, "brownish yellow" color was perceived in vacuum-fried pulps from thin and thicker pulp and "golden yellow to brownish yellow" color was noted in thick pulps. For aroma, regardless of the thickness, the products were perceived to have "perceptible jackfruit aroma". For taste, a "sweet taste" was perceived in products from thin and thicker pulps while moderately sweet taste was described in products from thick pulps. For texture, a "very crispy" texture was perceived in vacuum-fried product from thin and thick pulps and "crispy texture" was perceived in thicker pulps. Thick pulps were described "moderately oily" while thin and thicker pulps were perceived as slightly oily.

Table 11. Quality description of vacuum-fried jackfruit as influenced by the thickness of pulp used

\begin{tabular}{cccccc}
\hline \multirow{2}{*}{$\begin{array}{c}\text { Pulp } \\
\text { Thickness }\end{array}$} & Color & Aroma & Taste & Texture & Oiliness \\
\cline { 2 - 4 } Thin & $\begin{array}{c}\text { Brownish } \\
\text { yellow }\end{array}$ & $\begin{array}{c}\text { Perceptible } \\
\text { jackfruit } \\
\text { aroma }\end{array}$ & Sweet & Very crispy & Slightly oily \\
Thick & $\begin{array}{c}\text { Golden } \\
\text { yellow to } \\
\text { brownish } \\
\text { yellow }\end{array}$ & $\begin{array}{c}\text { Perceptible } \\
\text { jackfruit } \\
\text { aroma }\end{array}$ & $\begin{array}{c}\text { Moderately } \\
\text { sweet }\end{array}$ & $\begin{array}{c}\text { Crispy to very } \\
\text { crispy }\end{array}$ & $\begin{array}{c}\text { Moderately } \\
\text { oily }\end{array}$ \\
Thicker & $\begin{array}{c}\text { Brownish } \\
\text { yellow }\end{array}$ & $\begin{array}{c}\text { Perceptible } \\
\text { jackfruit } \\
\text { aroma }\end{array}$ & Sweet & Crispy & Slightly oily \\
\hline
\end{tabular}


General Acceptability. Table 12 summarizes the mean acceptability ratings of the sensory attributes of vacuum-fried jackfruit as affected by pulp thickness. Results revealed that pulp thickness did not significantly influence the mean acceptability ratings of the sensory attribute of the product. Regardless of the pulp thickness used, the vacuum-fried product got a mean acceptability rating that corresponds to "like moderately". Although the mean acceptability rating for texture attribute of vacuum product from thin pulps is significantly higher than thick and thicker pulps, however, their rating does not significantly differ.

Table 12. Mean ${ }^{1}$ acceptability ratings ${ }^{2}$ of the sensory attributes of vacuum-fried jackfruit as influenced by pulp thickness

\begin{tabular}{ccccccc}
\hline \multirow{2}{*}{ Thickness } & \multicolumn{7}{c}{ Sensory Attributes ${ }^{\text {ns }}$} \\
\cline { 2 - 6 } & Color & Aroma & Taste & Texture & Oiliness & Gen. Acc. \\
\hline Thin & 7.40 & 7.38 & 7.50 & 8.02 & 7.47 & 7.78 \\
Thick & 7.38 & 7.58 & 7.68 & 795 & 7.38 & 7.75 \\
Thicker & 7.63 & 7.63 & 7.63 & 7.80 & 7.45 & 7.35 \\
\hline
\end{tabular}

${ }^{1} \mathrm{~N}=32$

${ }^{2}$ Range of scores:

9 -like extremely $\quad 7$-like moderately 5 -neither like nor dislike 3 -dislike moderately

8 -like very much 6 -like slightly $\quad 4$-dislike slightly 2 -dislike very much

1 - dislike extremely

\section{Consumer Acceptability}

Consumer acceptability towards vacuum-fried jackfruit as influenced by pulp thickness is presented in Table 13. Of the 100 consumers, $90 \%$ liked the vacuumfried jackfruit from thin pulp; $93 \%$, the thick pulp; $96 \%$, the thicker pulp; and $92 \%$, the control. Common comment about the likability of the product was on its unique taste and crunchiness. Some consumers said that they could not detect any difference between the sample and the rest of the samples evaluated.

Table 13. Acceptability of vacuum-fried jackfruit as influenced by pulp thickness

\begin{tabular}{cccc}
\hline \multirow{2}{*}{ Samples } & \multicolumn{3}{c}{ Consumer Response $^{1}$} \\
\cline { 2 - 4 } & Like & Dislike & No Comment \\
\hline Thin (A) & 90 & - & 10 \\
Thick (B) & 93 & - & 7 \\
Thicker (C) & 96 & - & 4 \\
Control (D) & 92 & - & 8 \\
\hline
\end{tabular}

${ }^{1} \mathrm{~N}=100$ respondents composed of students, faculty, staff and guests of VSU

\section{Pulp Size}

Quality Description. The quality description of the sensory attributes of vacuum-fried jackfruit as influenced by pulp size is presented in Table 14. In terms of 
Effects of selected fruit development factors on the quality and acceptability of vacuum-fried

color, "golden yellow" to "brownish yellow" was discerned in vacuum-fried pulp from small bulbs and "brownish yellow" from medium bulbs while "golden yellow" describe the color of pulps from large bulbs. For aroma, a "perceptible jackfruit aroma" was perceived in vacuum-fried pulps regardless of the size of pulp used. The same observation was noted in terms of taste and oiliness. "Sweet taste" and "slightly oily" was perceived in the product regardless of the pulp size. For texture, a "crispy" description was given to product from small bulb while "very crispy texture" with those from medium and large pulps. For oiliness, results show that regardless of pulp size, the product was perceived "slightly oily".

Table 14. Quality description of the sensory attributes of vacuum-fried pulp as influenced by fruit pulp size

\begin{tabular}{|c|c|c|c|c|c|}
\hline \multirow{2}{*}{ Pulp Size } & \multicolumn{5}{|c|}{ Sensory Attributes } \\
\hline & Color & Aroma & Taste & Texture & Gen. Acc. \\
\hline Small & $\begin{array}{l}\text { Brownish } \\
\text { yellow to } \\
\text { brownish }\end{array}$ & $\begin{array}{c}\text { Perceptible } \\
\text { jackfruit } \\
\text { aroma }\end{array}$ & Sweet & Crispy & Slightly oily \\
\hline Medium & $\begin{array}{l}\text { Brownish } \\
\text { yellow }\end{array}$ & $\begin{array}{c}\text { Perceptible } \\
\text { jackfruit } \\
\text { aroma }\end{array}$ & Sweet & Very crispy & Slightly oily \\
\hline Large & $\begin{array}{l}\text { Golden } \\
\text { yellow }\end{array}$ & $\begin{array}{c}\text { Perceptible } \\
\text { jackfruit } \\
\text { aroma }\end{array}$ & Bland & Crispy & Slightly oily \\
\hline
\end{tabular}

General Acceptability. Table 15 shows that of the sensory attributes evaluated, only taste attribute was significantly affected by pulp size. Of the sizes evaluated, small and medium size pulps got a mean taste acceptability rating of 7.67 and 7.50 , respectively, corresponding to "like moderately" and did not significantly differ from each other. Large size pulp got a mean taste acceptability rating of 6.60 equivalent to "like slightly" and significantly lower than small and large pulp. The mean acceptability ratings of other attributes like color, aroma, texture, oiliness and general acceptability were not significantly influenced by the pulp size.

Table 15. Mean ${ }^{1}$ acceptability ratings ${ }^{2}$ of the sensory attributes of vacuum-fried jackfruit as influenced by pulp size

\begin{tabular}{ccccccc}
\hline \multirow{2}{*}{ Pulp Size } & \multicolumn{5}{c}{ Sensory Attributes } \\
\cline { 2 - 5 } & Color $^{\text {ns }}$ & Aroma $^{\text {ns }}$ & Taste $^{\star \star}$ & Texture $^{\text {ns }}$ & Oiliness $^{\text {ns }}$ & Gen. Acc. $^{\text {ns }}$ \\
\hline Small & 7.40 & 7.73 & $7.67 \mathrm{a}$ & 7.77 & 7.57 & 7.57 \\
Medium & 7.28 & 7.68 & $7.50 \mathrm{a}$ & 7.87 & 7.67 & 7.55 \\
Large & 7.78 & 7.58 & $6.60 \mathrm{~b}$ & 7.80 & 7.65 & 7.17 \\
\hline
\end{tabular}

${ }^{1} \mathrm{~N}=32 \quad$ ns - not significant $\quad * *$ - highly significant at $\mathrm{p} \leq 0.005$.

${ }^{2}$ Range of scores:

9 -like extremely 7 -like moderately 5 -neither like nor dislike

8 -like very much 6 -like slightly
5 - neither like nor dislike 3 -dislike moderately

4-dislike slightly 2-dislike very much 


\section{Consumer Acceptability}

Table 16 presents the result in consumer evaluation of vacuum-fried jackfruit as influenced by pulp size thickness. Of the 100 consumer panelists, $98 \%$ liked the vacuum-fried product from small fruit pulps, $95 \%$ liked the medium size pulps, $92 \%$ liked the large pulp and $89 \%$ liked the control. The comments on the vacuum-fried product from 88-day old pulps were "the color was attractive" and "dominant jackfruit taste".

Table 16. Acceptability of vacuum-fried jackfruit pulps as influenced by pulp size

\begin{tabular}{cccc}
\hline \multirow{2}{*}{ Samples } & \multicolumn{3}{c}{ Consumers Response $^{1}$} \\
\cline { 2 - 4 } & Like & Dislike & No Comment \\
\hline Small & 98 & - & 2 \\
Medium & 95 & - & 5 \\
Large & 92 & - & 8 \\
Control & 89 & - & 11 \\
\hline
\end{tabular}

${ }^{1} \mathrm{~N}=100$ respondents composed of students, faculty, staff and guests of VSU.

\section{CONCLUSION}

Fruit maturity has significant influence on the sensory qualities of vacuum-fried jackfruit pulp. Vacuum-fried pulp from 91-day fruit got a golden yellow color, perceptible jackfruit aroma, moderately sweet taste and moderately oily. Maturity is critical in the production of vacuum-fried jackfruit. The ideal fruit maturity for production of vacuum-fried pulp that got $98 \%$ acceptability from consumers was 88 days after fruit bagging.

Fruit location influenced $\mathrm{pH}, \mathrm{TSS}$, TTA but not on pulp thickness. It has no significant effect on the mean acceptability rating of color, aroma, texture, oiliness and general acceptability while significant effect was noted on the taste acceptability of the vacuum fried pulp. All the samples were highly acceptable to consumers.

Pulp location has significant effect on $\mathrm{pH}$, TSS and thickness of the pulp but not on percent TTA of the pulp. Fruit location has no significant effect on the mean acceptability rating in almost all of the sensory parameters studied except taste. Regardless of the pulp location in fruit, the vacuum-fried pulp is acceptable.

Pulp thickness has no significant influence on the sensory attributes of the product while pulp size significantly affected only the taste acceptability. Regardless of the size and thickness of the pulp, the product is acceptable. Vacuum-fried jackfruit is acceptable to consumers regardless of their size and thickness. 
Effects of selected fruit development factors on the quality and acceptability of vacuum-fried

\section{REFERENCES}

Association of Official Analytical Chemists. 1980. In Horwitz W (ed) Official Methods of Analysis of Association of Official Analytical Chemists (13th edn). Washington D.C. USA

Coronel RE. 1983. Processing Fruits of the Philippines (pp508). Published by the College of Agriculture. University of the Philippines Los Banos, Laguna

Daclag JG. 2018. Nutritional Sustainability and Quality Vacuum Fried 'EVIARC Sweet' Jackfruit (Artocarpus heterophyllus Lam.) as Affected by Fruit Maturity and Packaging Methods

Diamante LM. 2007. Development of vacuum fried products from ripe jackfruit. A paper presented during the 19th VICARP R \& D regional Symposium at LSU Visca, Baybay City. May 24-25, 2007

Galvez LA and Dizon El. 2017. Physico-chemical and Functional Properties of Two Jackfruit (Artocarpus heterophylus Lam.) Varieties in Eastern Visayas, Philippines. Annals of Tropical Research 39(2):100-106

Lauzon RD, Amestoso FJ, Galvez LA \& Varron DAC. 2014. Processing of High Value Product from Jackfruit. PCAARRD Funded Research. Terminal Report

Mabesa LB. 1986. Sensory Evaluation of Foods: Principles and Method. Published by College of Agriculture. University of the Philippines, Los Banos, Laguna

Meyer LH. 1971. Food Chemistry (Ninth printing) (pp385). Reinhold Publishing Corporation, New York

Morton JF. 1987. Jackfruit and Related Species. In Fruits of Warm Climates. Retrieved from https://hort.purdue.edu/newcrop/morton/jackfruit_ars.html

Raymundo LC. 1985. Lecture Paper on Food Biochem (Unpublished). Institute of Food Science and Technology, University of the Philippines Los Banos

Swani SB, Thakor NJ, Haldanker PM \& Kalse SB. 2012. Jackfruit and Its Many Functional Components as Related to Human Health. A Review. Comprehensive Reviews in Food Science and Food Safety 11(6):565-576. https://doi.org/10.1111/j.1541-4337.2012.00210.x 